\title{
Split hand-split foot-deafness syndrome
}

INSERM

\section{Source}

INSERM. (1999). Orphanet: an online rare disease and orphan drug data base. Split handsplit foot-deafness syndrome. ORPHA:71271

Split hand - split foot - deafness is an extremely rare genetic syndrome reported in a few families to date and characterized clinically by split hand/split foot malformation (SHFM; see this term) and mild to moderate sensorineural hearing loss, sometimes associated with cleft palate and intellectual deficit. 